\title{
Elective ventilation as an improvement measure in organ and tissue donation process
}

\author{
F Segura ${ }^{{ }^{*}}$, D Daga ${ }^{1}$, A Puerto ${ }^{1}$, J Pérez-Vacas ${ }^{1}$, A Fernández-Porcel ${ }^{1}$, MA Frutos $^{2}$ \\ From ESICM LIVES 2015 \\ Berlin, Germany. 3-7 October 2015
}

\section{Introduction}

Elective Ventilation (EV) is a concept that consists on the agreement reached between patient relatives and transplant coordinator of intubate, connect to mechanical ventilation and admit in intensive care unit those people who are in a coma secondary to a catastrophic cerebral vascular accident (CVA), with the only purpose of becoming organ donors after brain death state has been set.

\section{Objectives}

EV protocol impact assessment in donation and transplant hospital programme.

\section{Methods}

Descriptive retrospective study of a series of patients to whom EV was applied during years 2013-2014 at Hospital Universitario Virgen de la Victoria in Málaga. Before relatives interview, it was made sure that the patient case had been neurosurgically dismissed, that there was not obvious donation contraindication and that, one organ at least, met analytic and ecographic criteria of potential viability. Different criteria were analysed such as age, brain death cause, time to brain death, viable organs extracted, relative weight of EV donors among all the effective donors and relatives refusal percentage. Categoric variables shown as numbers and percentages, quantitative variables in terms of median and standard deviation.

\section{Results}

$16 \mathrm{EV}$ candidates were registered. After two relative refusals $(12.5 \%)$, EV was finally applied to 14 patients. The series age was set in $77.07 \pm 9.15$ years. 12 of the total CVA (75\%) were hemorrhagic. In all cases, brain death was determined after $2.21 \pm 2.00$ days of admission.
Twelve of these patients generated 23 valid organs (85.71\%, 1.64 organs per patient), making one cardiac, 10 liver and 12 renal transplants possible, meaning 50\% of total cardiac transplants, $45.45 \%$ of liver transplants and $24 \%$ of renal transplants; and globally $31.08 \%$ of the total number of transplants generated in our hospital during the study period.

\section{Conclusions}

Potential donors inclusion in EV protocol has led to a remarkable increase in the number of organs available for transplant in our hospital, with an acceptable number of relatives refusals. Despite the age profile of the patients, $85 \%$ of them generated viable organs for transplant.

\section{Authors' details}

${ }^{1}$ Hospital Universitario Virgen de la Victoria, ICU, Málaga, Spain. ${ }^{2}$ Transplant Coordination, Sector Málaga, Málaga, Spain.

Published: 1 October 2015

\section{References}

1. de Lora Pablo, Blanco Pérez Alicia: Dignifying death and the morality of elective ventilation. J Med Ethics 2013, 39:145-148, doi: 10.1136/medethics2012100995.

2. Baumann Antoine, Audibert Gèrard, Lafaye Guibet Carolinie, et al: Elective non-therapeutic intensive care and the four principles of medical ethic. J Med Ethicvs 2013, 39:139-142, doi: 10.1136/medethics-2012100990.

doi:10.1186/2197-425X-3-S1-A900

Cite this article as: Segura et al.: Elective ventilation as an improvement measure in organ and tissue donation process. Intensive Care Medicine Experimental 2015 3(Suppl 1):A900. 